\title{
Retrospective study on the fetal maldispositions as a cause of dystocia in Egyptian buffalo-cows: strategic plan to improve
}

\section{Editorial}

The important for economic production of rapidly returning animals to pregnancy after they have given birth require that the pregnancy is confirmed or as soon as possible after service. Parturition is a critical time for both dam and calf and is particularly difficult for a first-calving cow, because of her inexperience and the small size of the pelvis through which the calf has to pass. Many inexperience herdspeople are eager to give as much help as possible. A common error, especially by inexperienced personnel, is to get anxious and pull a calf too soon. If the cervix has not had sufficient time to dilate, forcing the calf can seriously injure the cow and cause undo stress to the calf. Heifers spend more time in labor and more time giving birth than mature cows.

Dystocia is a problem most dairy producer's encounter. It is defined as delayed or difficult calving, sometimes requiring significant human assistance. ${ }^{1,2}$ It has a considerable impact on production and future reproduction of dairy ${ }^{3,4}$ and beef ${ }^{5,6}$ animals. The effects of dystocia on subsequent reproduction were reflected to a greater extent by conception rate and percent- age of the cows returning to estrus during the AI period than by the other reproductive parameters that were evaluated.

Two symptoms of dystocia are extended calving periods (over 8hours) and evidence that the fetus is not oriented properly for a normal birth. If the cow has not delivered in the specified time or the calf is malpresented, veterinary assistance is often indicated. In Egypt, especially in Upper Egypt, the cost of calf mortality resulting from dystocia averages $1500 \mathrm{LE}$ for every calving. The cost of labor, veterinary care and a longer calving interval probably triples that cost.

Various types of fetal dystocia due to fetal maldispositions have been reported in cattle and buffalo. The normal parturient presentation and position assumed by the normal fetus at the time of delivery is the cranial presentation dorso-sacral position with extended forelimbs and head resting on metacarpal bones. Any presentation or position other than this is likely to cause dystocia. Abnormal positions and postures are described for cranial (anterior) and caudal (posterior) presentations separately. The total incidence of dystocia due to fetal maldispositions described for the buffalo vary from 45.426 to $69.8 \%$. In dairy cattle, Wehrend et al., ${ }^{8}$ have observed that incorrect fetal orientation of a dead fetus was the most frequent cause $(38.9 \%)$ of dystocia and similar findings were recorded by Holland et al. ${ }^{9}$

\section{Case analysis and discussion}

In this study, a retrospective analysis was carried out on $543(58.262 \%)$ cases of dystocia in buffalo-cows from a total number of 932 cases of dystocia in all animals which presented at our Educational Veterinary Hospital, Faculty of Veterinary Medicine, Assiut University, Egypt during the period 2008 to 2015. The animals were brought by both local owners and those living further afield. The method adopted to correct the dystocia and fetal survival depends
Volume 3 Issue 5 - 2016

\author{
Gaber Ahmed Megahed \\ Theriogenology Department, Assiut University, Egypt
}

Correspondence: Gaber Ahmed Megahed,Theriogenology Department, Faculty of Veterinary Medicine, Assiut University, Egypt, Email gabermegahed@yahoo.com

Received: July 04, 2016 | Published: July 18, 2016

upon the time of presentation of the animal after the onset of second stage of labor and the expertise available.

Fetal dystocia was common in buffalo-cow comprising $60.957 \%$ of total cases presented, whereas maternal causes constituted 39.043 $\%$ of total cases. Nearly similar observations were recorded by Buchoo et al., ${ }^{10}$ and Khammas \& AlHamedawi et al. ${ }^{11}$ However, this is disagreement with that reported by Purohit et al., ${ }^{12}$ who recorded that in buffalo, maternal dystocia was common (59.82\%) compared to fetal dystocia $(40.17 \%)$. Most of the buffalo-cows presented were in their first parity $(24.31 \%)$ as well as, we noticed that, $31.12 \%$ in their second parity and $44.57 \%$ in their third and more parity. The total incidence of fetal cause of dystocia in buffalo at our Educational Veterinary Hospital, Faculty of Veterinary Medicine was $60.957 \%$ from which about 90.634 and $9.366 \%$, due to fetal maldispositions and oversized fetus. This is in agreement with Kamlesh et al., ${ }^{13}$ who conculded that Maldisposition of fetus was the commonest cause of fetal dystocia in buffaloes, however they recorded a smaller ratio $(18.03 \%)$ from that recorded in this study.

In this study, the most common cause of dystocia seems to be fetal maldispositions, of which limb flexion and head deviation appear to be the most frequent. This is in agreement with that mentioned by Wehrend et al., ${ }^{8}$ Purohit et al. ${ }^{14-16}$

\section{Now how to avoid or reduce this problem?}

Generally, preventing dystocia depends on how far along a cow or heifer is in her pregnancy. For example, if a female is only days away from parturition, there's no way you can prevent dystocia: it's just too late. On the other hand, if a female is in her second or third trimester of pregnancy, measures can be taken to lower a calf's weight in the womb, and that is limiting the amount of protein and energy that is fed to a cow, especially in her last trimester. Fetuses tend to increase in growth in the last trimester than in the first two trimesters, and limiting what the cow gets per feed quality may decrease calf 
birth weight. Increasing in energy and protein intake doesn't always go directly to the cow, but to the fetus, because it's the fetus that pulls all those nutrients from the cow through the umbilical cord in order to grow.

Concerning the fetal causes especially fetal maldisposition, avoid dystocia will be done through observation of the cows/heifers close to calving - early intervention can help prevent some of the more difficult dystocias and calf deaths. As well as, educating your personnel - Knowing when to intervene and what to do is extremely important in decreasing the occurrence of more difficult dystocias and calf death losses.

Finally, attribute this high rate of fetal maldisposition in our study to the intervention of the owner of the animal at the beginning of birth (i.e., at the beginning of the stage of opening the cervix). This interference leads to degradation of the natural development of the fetus during childbirth (and this intervention in terms of helping the cow out of fear of suffocation fetus) but this intervention should be prevented. After studying this phenomenon, it was necessary to develop a strategic plan to improve the difficult birth rates in buffaloes in Egypt.

The strategic plan included two parts:

A. The first part includes a hold training and education sessions for the owners as:

i. It make clear to the owner, it should recognize impending calving and, if difficulties are anticipated, it is better to bring the animal to a clinic due to the veterinaries should be assistance.

ii. Knowledge of the economic losses resulting from dystopia on production and reproduction are poorly documented.

iii. Knowledge of this, plus associated losses in calves and cows having difficult births is needed to determine if selection should be practiced for calving ease and how much emphasis calving ease should receive relative to production, reproduction, and other traits.

iv. And also add part taught to students in the final years of the study and this part includes:

v. How to communicate with the animal owners and breeders?

vi. Provide technical support and awareness for the owners of the animal.

vii. As well as educate students on the task of not only veterinarian treatment or solution to the reproductive problems of animal, but must be follow-up after treatment.

viii. And also to educate and explain the reasons that led to this case to the owner of the animal so as not to repeat the problem.

ix. This is done through counseling sessions and awareness and this leads to reduce the difficulty of the process of birth in the animal.

B. The second part of the strategic plan includes the measurement of the feedback after this awareness and guidance for the owners of the animal. This part will be conducted in the future through data collection and analysis to measure the benefit of this strategic plan.

\section{Acknowledgements}

None.

\section{Conflict of interest}

Author declares that there is no conflict of interest.

\section{References}

1. Lombard JE, Garry FB, Tomlinson SM, et al. Impacts of dystocia on health and survival of dairy calves. J Dairy Sci. 2007;90(4):1751-1760.

2. Zaborski D, Grzesiak W, Szatkowska I. Factors affecting dystocia in cattle. Reprod Dom Anim. 2009;44(3):540-551.

3. Berry DP, Lee JM, Macdonald KA, et al. Body condition score and body weight effects on dystocia and stillbirths and consequent effects on post calving performance. J Dairy Sci. 2007;90(9):4201-4211.

4. Gaafar HMA, Shamiah SM, El-Hand MAA.Dystocia in Friesian cows and its effects on postpartum reproductive performances and milk production. Trop Anim Health Prod. 2011;43(1):229-434.

5. Berger PJ, Cubas AC, Koehler KJ, et al. Factors affecting dystocia and early calf mortality in Angus cows and heifers. J Anim Sci. 1992;70(6):1775-1786.

6. Casas E, Thallman RM, Cundiff LV. Birth and weaning traits in crossbred cattle from Hereford, Angus, Brahman, Boran, Tuli and Belgian Blue sires. J Anim Sci. 2011;89(4):979-987.

7. Danny B Laster, Hudson A Glimp, Larry V Cundiff, et al. Factors affecting dystocia and the effects of dystocia on subsequent reproduction in beef cattle. J Anim Sci. 1973;36(4):695-705.

8. Wehrend Reinic T, Herfen K, Bostedt H. Fetotomy in cattle with special references to post operative complications: an evaluation of 131 cases. Dtsch Tierarztl Wochenschr. 2002;109(2):56-61.

9. Holland MD, Speer NC, Lefever DG. Factors contributing to dystocia due to fetal malpresentation in beef cattle. Theriogenol. 1993;39(4):899-908.

10. Buchoo BA, HK Bhattacharyya, MR Fazili. A field study on the incidence of Dystocia in cattle. Indian Vet J. 2008;85(12):1342-1343.

11. Khammas DJ, Al-Hamedawi TM. Clinical investigation of bovine dystocia in Iraq. Indian Vet J. 1994;71(5):464-468.

12. Purohit GN, Kumar P, Solanki K, et al. Perspectives of fetal dystocia in cattle and buffalo. Veterinary Science Development. 2012;2(1):e8.31$\mathrm{e} 8.42$

13. Kamlesh J, Purohit GN, Mehta JS, et al. A retrospective study on incidence of dystocia in cattle and buffaloes at referral center. Theriogenology Insight. 2015;5(1):41-45.

14. Purohit GN, Barolia Y, Shekher C, et al. Maternal dystocia in cows and buffaloes: a review. Open J Anim Sci. 2011;1(2):41-53.

15. Purohit GN, Barolia Y, Shekhar C, et al. Diagnosis and correction of uterine torsion in cattle and buffaloes. Raksha Techn Rev. 2011;1(2):11-17.

16. Purohit GN, Mehta JS. Dystocia in cattle and buffaloes. A retrospective analysis of 156 cases. Vet Practitioner. 2006;7(1):31-34. 